\title{
Study on the Shape Optimization of Composite Slope at the End of Irregular Boundary Open-Pit Mine
}

\author{
Haoran $\mathrm{Li}^{1}{ }^{*}$, Runcai Bai ${ }^{1}$, Guangwei Liu ${ }^{1}$, Han $\mathrm{Du}^{2}$, Jing Zhang ${ }^{*}$, Jinwen $\mathrm{Xu}^{3}$ \\ ${ }^{1}$ Liaoning Technical University, Institute of Mining, Liaoning, Fuxin, China \\ ${ }^{2}$ Department of Hydraulic Engineering, State Key Laboratory of Hydroscience and Engineering, \\ Tsinghua University, Beijing, China \\ ${ }^{3}$ East open-pit mine of China Coal Pingshuo group, Shuozhou, China \\ *Corresponding Author.
}

\begin{abstract}
In order to optimize the shape of the compound slope at the end of the open-pit mine under the condition of nonirregular boundary, the compound slope composed of the stope end and the inner dump in the south of the open-pit mine in Pingshuo is studied. Due to the impact of land acquisition, the space of external dump is seriously insufficient, and with the development and change of mining engineering and the influence of geological structure, the problem of compound form optimization and the release and utilization of internal drain space in the south side is generated. Through field investigation and theoretical analysis and numerical analysis method, on the basis of investigating the ore party production status, to establish a 3 d geological model, select two battery profile typical position, using rigid body limit equilibrium method from the perspective of $2 d$, in the full study south help shrink battery limit compound stope side slope and mine safety distance, flat width, and the direction of dump active line and the relationship between the stability design of multiple slope configuration scheme, through the various methods of slope stability, enforceability and comparing some important parameters such as displacement capacity, ultimately determine the technology feasible economic and reasonable boundary zone composite slope space form. Based on the above research results, FLAC3D software was used to study the stress-strain relationship inside the slope, revealing the deformation and failure mechanism and stability of the composite slope in the south bound area. The results show that the landslide mode and stability of the composite slope in the south bound area of pingshuo Andaobao open-pit coal mine are mainly controlled by the safe distance between stope and dump and the weak layer of 11 coal floor. According to the design, the economic and reasonable parameters of the composite slope in the south slope shrinkage boundary area are as follows: the safe distance between the stope end side and the dump site is 50m, the width of the dump flat plate is $60 \mathrm{~m}$, and the working line Angle of the dump line with the abandonment height of $255 \mathrm{~m}$ is $125^{\circ}$, the total discard space was $95,934,100 \mathrm{~m}^{3}$.
\end{abstract}

Keywords: irregular boundary; open-pit mine; composite slope; land expropriation; shape optimization; the numerical model

\section{Introduction}

With the increasing demand for energy, the production capacity and scale of open-pit mines are increasing year by year. Therefore, the optimal design of the side slope form has become an important research topic in the production and development of open-pit mines ${ }^{[1-5]}$. As the inner dumps develop continuously in various open-pit mines, the morphological optimization of the composite side slope, which is formed by the stope and the dump in open-pit mines, restricts the production of open-pit mines ${ }^{[6] .}$

At present, scholars at home and abroad have conducted considerable research on the form optimization of the composite side slope in generic forms. Cao Lanzhu et al. ${ }^{[7-8]}$ focused on the form design of the composite soil-rock anti-dip side slope in open-pit mines with boundaries and obtained the side slope form by using the rigid equilibrium limit method and the three-dimensional numerical simulation method. Bai Runcai et al ${ }^{[9]}$ studied the ISSN: 0010-8189 
stability of the composite side slope in open-pit mines by using the reverse checking algorithm of the part subdivision control. Li Rongwei et al ${ }^{[10]}$ found that the composite side slope composed of the outer dump and the excavation slope might get instable under the influence of groundwater. Sun Chengliang ${ }^{[11]}$ designed and calculated the reasonable boundary side slope form of open-pit mines based on the north slope project of the outer dump in Yilan open-pit mine. Crusoe et al ${ }^{[12]}$ studied the deformation and failure mechanism of the composite side slope in open-pit mines and analyzed the influence of the weak floor occurrence on the stability of the composite side slope. Ruo Rui et al ${ }^{[13]}$ combined the limit equilibrium method with the finite element method to calculate and analyze the stability of the side slope. Zheng Yingren et al $^{[14]}$ studied the stability of rock and soil slope by using the finite element method of strength reduction, and found that the constriction of force and displacement was a reasonable criterion to judge the side slope breakage after a detailed analysis of the operation precision and influencing factors of the finite element method of strength reduction. Liu Rucheng et al. ${ }^{[15]}$ analyzed the failure mechanism of the slope instability according to the optimization theory, and determined the most dangerous slip surface position of the slope failure under the influence of weak lfloors. Yao Xiangji ${ }^{[16]}$, Tang Wenliang et al. ${ }^{[17]}$ analyzed the stability of the composite soil-rock slope in open-pit mines and determined the safe distance between the stope and the dump.

To sum up, the optimization of the composite slope form grows increasingly prominent in the open-pit mine production, but very few studies have touched upon the problems of the composite slope with irregular boundaries on the end slope. The paper selected the composite slope of the southern boundary limit at Antaibao open-pit mine in Pingshuo mining area, Shuozhou in Shanxi Province, which is caused by land acquisition, as the engineering background, and technological means such as field research, theoretical analysis and scheme comparison were used to determine the reasonable operation line development direction for dumping and the composite slope form that has the maximum dumping volume in the slope stability conditions. The research results of this paper not only guarantee the economical, safe and efficient operation of the open-pit mine but also provide a certain basis for the design and implementation of the composite slope project in similar conditions.

\section{Analysis of Geological Conditions in the Slope Project}

Pingshuo Antaibao open-pit mine is located at the northern end of Ningwu coal field. As the stope is advanced eastward and gets influenced by the anticline structure of the Luzi ditch, the dip angle of the coal bed suddenly increases. The floor of the coal bed drops from the height of about $+1280 \mathrm{~m}$ to $+1020 \mathrm{~m}$ to the east of the anticline influence zone. In some parts of the zone, the maximum decline reaches over $200 \mathrm{~m}$, which increases the thickness of the covering layer in the upper coal layer and the mining depth. Meanwhile, the stripping materials and the corresponding stripping ratio also rise. Great changes have taken place in mining technical conditions. Influenced by the land acquisition in the dump, the space of the outer dump is insufficient. In order to guarantee safety and improve economic benefits, the boundaries are limited at the southern end of Antaibao open-pit mine, so the boundary area is formed. This provides enough space for dumping and relieves the dumping pressure. In addition, it also causes the abrupt changes in the horizontal direction (east to west) on the earth's surface, and makes the overall mining boundary irregular. The limited boundary zone rises in the air towards north. At the western slope is 11 , the floor of the coal bed. Its dip angle is approximately $19^{\circ}$, and the length is $1000 \mathrm{~m}$ about from east to west and $800 \mathrm{~m}$ from south to north. The shape is an inverted triangle. At the bottom of the limited boundary zone, the depth drops to 1105 level, which is about $200 \mathrm{~m}$ away from the earth surface. The dumping is done horizontally in the boundary zone, and the eastern slope works as the retaining structure for the dump. The positions of the limited boundary zone are shown in Fig.1.

The strata of the limited boundary zone on the southern slope are the abandoned material layer, sandstone, 9 coal, sand and mudstones, 11 coal, and soft mudstone from top to bottom. When the basement of the dump is at $+1105 \mathrm{~m}$ level, the lithology of the stratum is sandstone. At the bottom of No. 11 coal bed is mudstones with relatively weak physical and mechanical indexes. As the slope and the dumping load constantly increase, the composite slope with a height of more than $300 \mathrm{~m}$ will be formed on the slope of the stope below $+1105 \mathrm{~m}$ and at the dump above $+1105 \mathrm{~m}$ after the soil is discharged in the southern limited boundary zone. Therefore, there is a great hidden danger

ISSN: 0010-8189 
of landslide. Physical and mechanical indexes of the rock and soil mass in various strata are shown in Table 1.

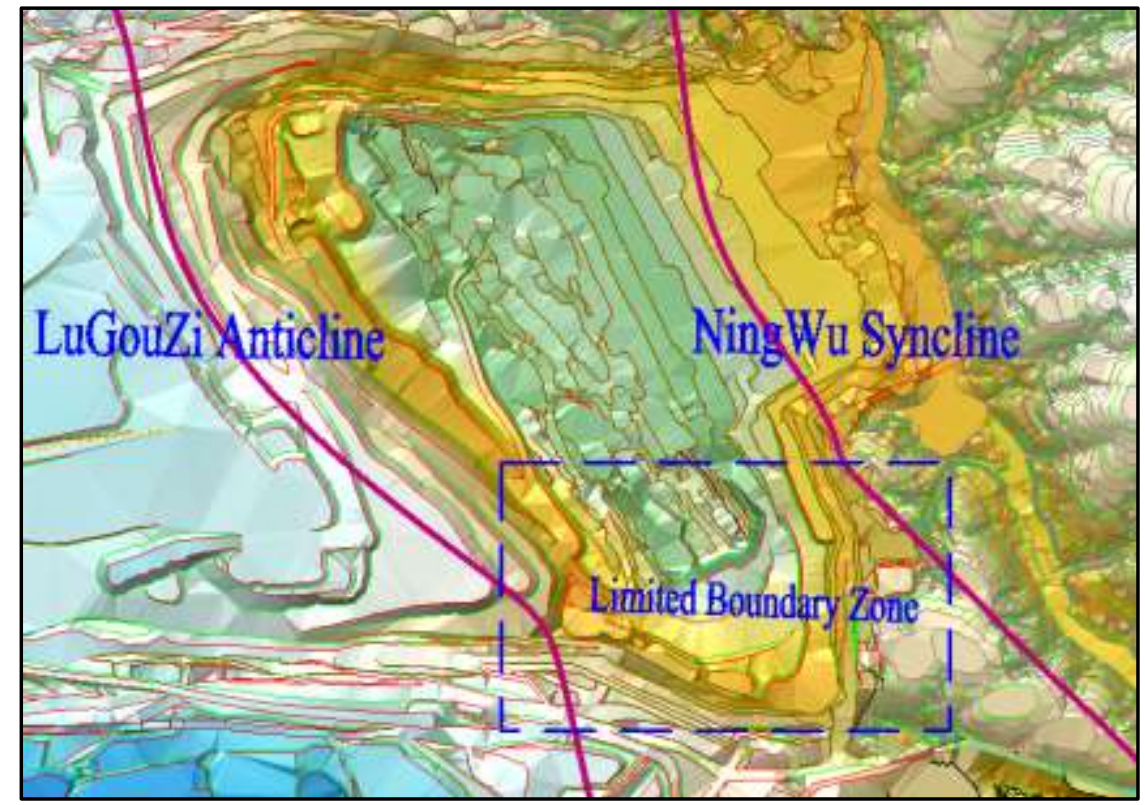

Fig.1: The positions of the limited boundary zone

Tab 1 Physical and mechanical parameters of rock and soil mass

\begin{tabular}{cccc}
\hline Name & Bulk density $\left(\mathrm{KN} / \mathrm{m}^{3}\right)$ & Cohesion $(\mathrm{Kpa})$ & Interior friction An $\left(^{\circ}\right)$ \\
\hline Wastes & 18.7 & $16-18$ & $16-18$ \\
Quaternary Loose Layer & 19.5 & $22-25$ & $21-22$ \\
4 Coal & 14.1 & 160 & 22 \\
9 Coal & 14 & 160 & 22 \\
11 Coal & 14.2 & 160 & 37.7 \\
Sandstone & 24.6 & 272 & 28 \\
Sand Shale Interbed & 24.6 & 300 & 16 \\
Weak Mudstone & 15 & 43 & 30 \\
Bedrock & 25.2 & 950 & \\
\hline
\end{tabular}

\section{Composite Slope Stability Analysis}

In order to optimize the design of the composite slope forms in the southern limited boundary zone, the paper is based on the comprehensive consideration of the geological characteristics of the composite slope project in the southern limited boundary zone of Antaibao open-pit mine. Two typical sections (both perpendicular to the working line of the inner dump) are selected for analysis and calculation, namely, I-I section and II-II section.The planemetric position of the geological section is shown in Fig. 2, and the geological section of the slope project is shown in Fig. 3.

ISSN: 0010-8189 


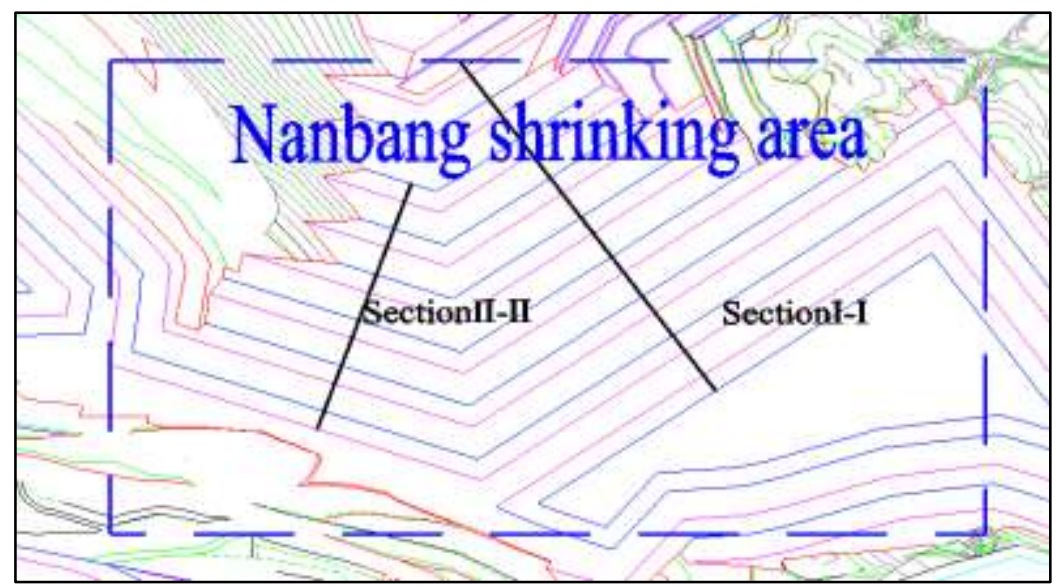

Fig.2: Sectional position plan

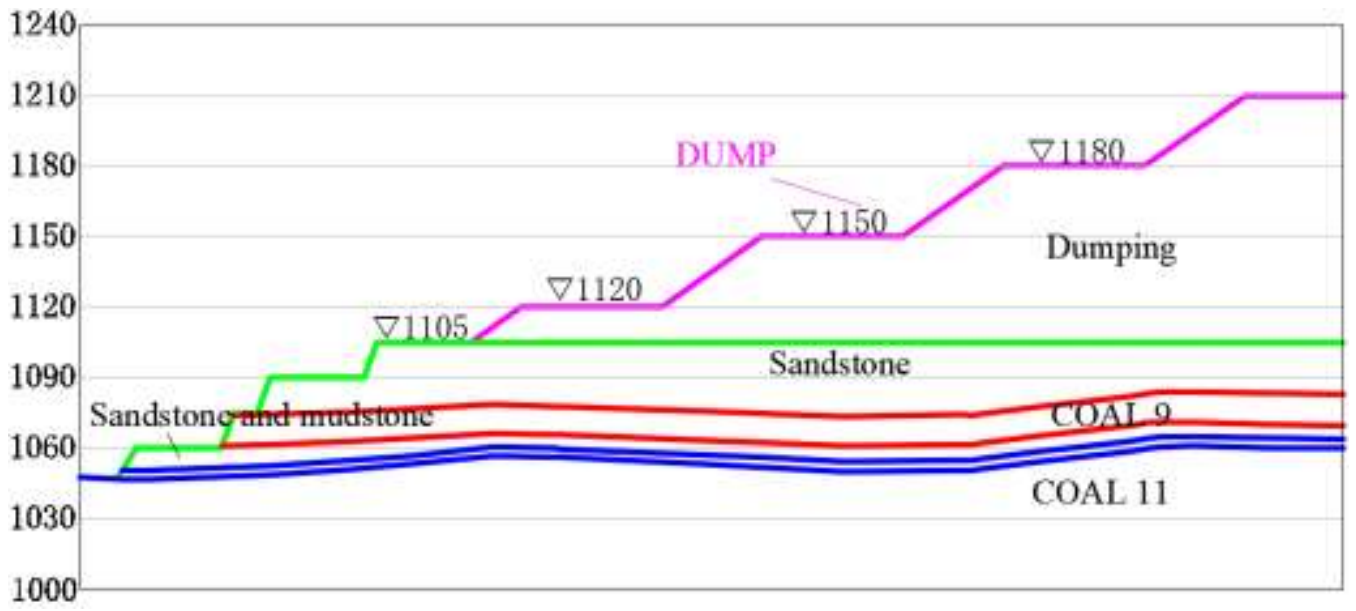

Fig.3: Slope engineering geological profile

\subsection{Safety reserve coefficient selection}

The limit equilibrium analysis method is used for slope safety evaluation and analysis. The safety reserve coefficient $\mathrm{K}$ is a quantitative parameter in the slope stability analysis and calculation, and its value is directly related to the fact whether the designed slope is economically feasible and safe and reasonable ${ }^{[18]}$. Based on the current understanding of structural conditions, regional geological conditions and the importance of slope at Antaibao open-pit mine, the following factors including the physical and mechanical indexes of rock and soil mass, service life, potential hazards, importance, etc. are taken into consideration while selecting the safety reserve coefficient for the calculation of the composite slope stability in accordance with the requirement in Codes For the Design of Open-Pit Mines in Coal Industry ${ }^{[19]}$ (GB50197-2015). And it is determined that the selected safety reserve coefficient of the slope should be 1.2 in the design and calculation of the composite slope in the southern limited boundary zone.

\subsection{Quantitative analysis of composite slope stability}

According to the field research, the dumping bench height is $30 \mathrm{~m}$, the bank slope is $35^{\circ}$, and the dumping elevation is 1,360 in the design of the southern limited boundary zone at Antaibao open-pit mine. To determine the optimum safe distance and the optimum dumped flat plate width between the dump and the stope slope of the limited boundary zone, this paper first makes a stability calculation of the composite slope of the dump when the dumping flat plate widths are different. Next, it obtains the dumping plan that satisfies the safety reserve coefficient and then compares different plans. Finally, it works out the plan of the maximum dumping quantity in the limited boundary

ISSN: 0010-8189 
zone on the premise of ensuring safety.

\subsubsection{I-I section slope stability calculation}

Regarding the slope engineering conditions of I-I section, when the safe distance between the stope lope and the dump is $40 \mathrm{~m}, 50 \mathrm{~m}$ and $60 \mathrm{~m}$, and the dumping flat plate width is $50 \mathrm{~m}, 55 \mathrm{~m}$ and $60 \mathrm{~m}$, respectively, the stability coefficient of the composite slope is designed and calculated. In all, nine composite slope forms of the limited boundary zone are obtained. The results of the stability coefficient calculation are shown in Fig. 4-6. The important indicators of each plan are shown in Table 2.

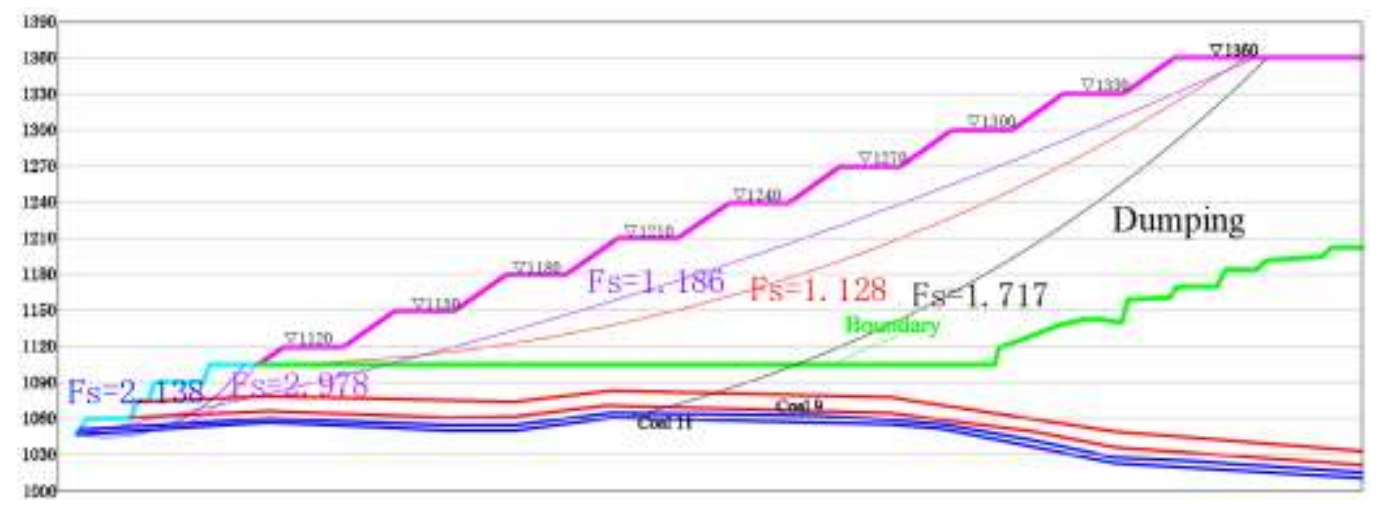

(a) Flat width $50 \mathrm{~m}$

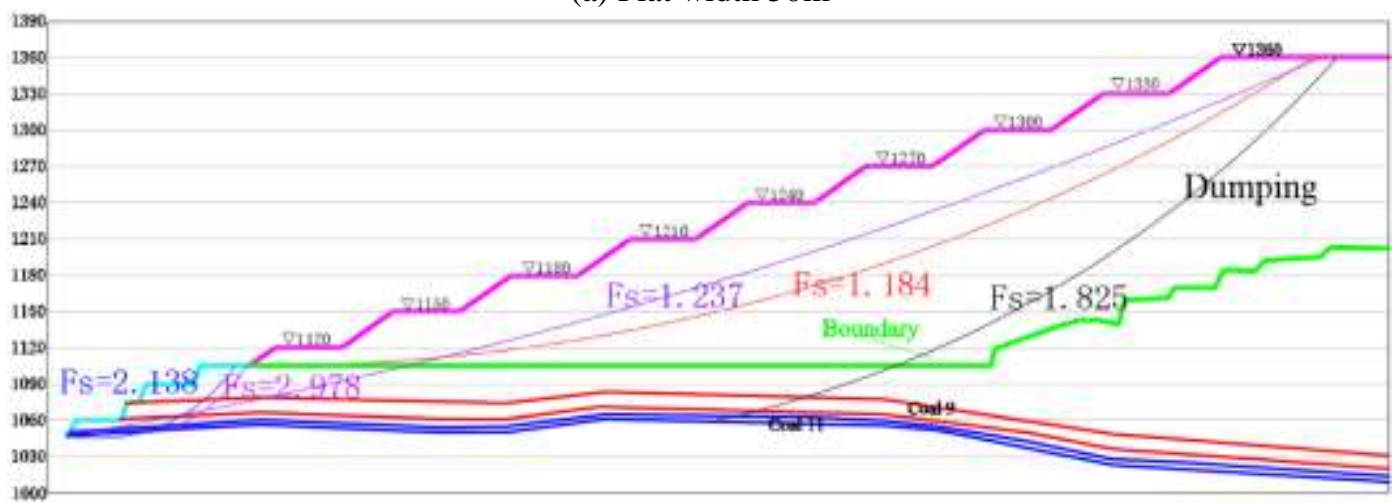

(a) Flat width $55 \mathrm{~m}$

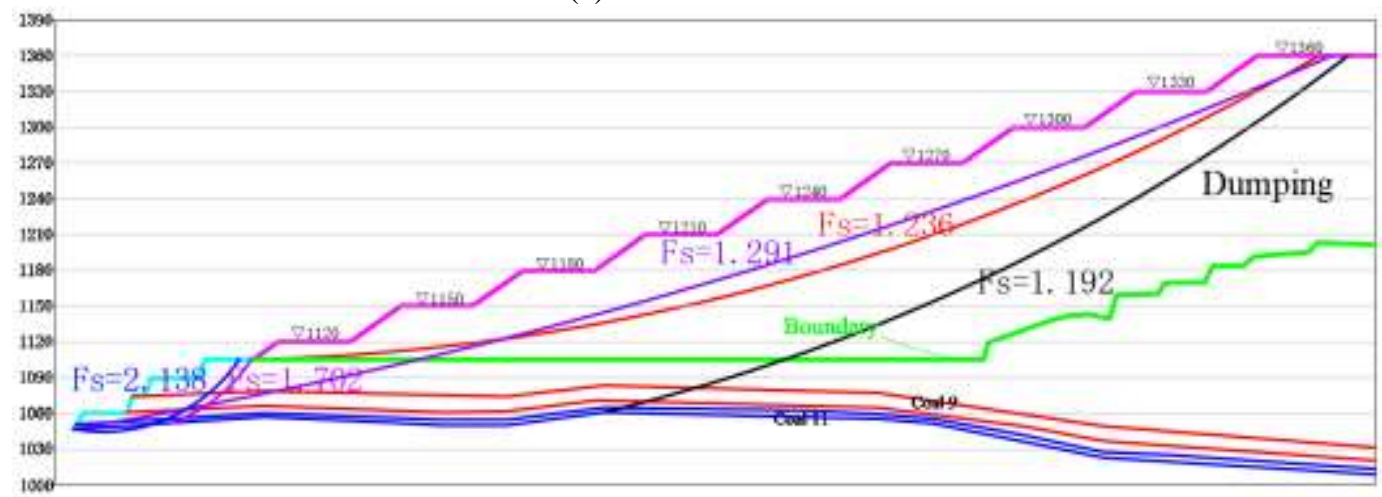

(a) Flat width $60 \mathrm{~m}$

Fig.4: Analysis results of slope stability in section I-I when the safe distance is $40 \mathrm{~m}$ 


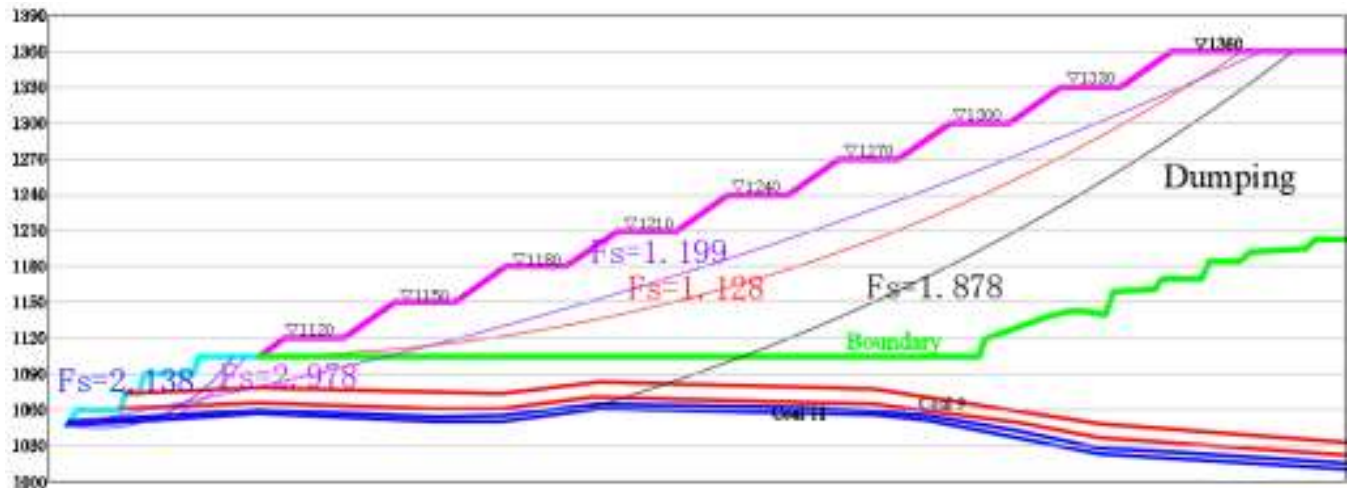

(a) Flat width $50 \mathrm{~m}$

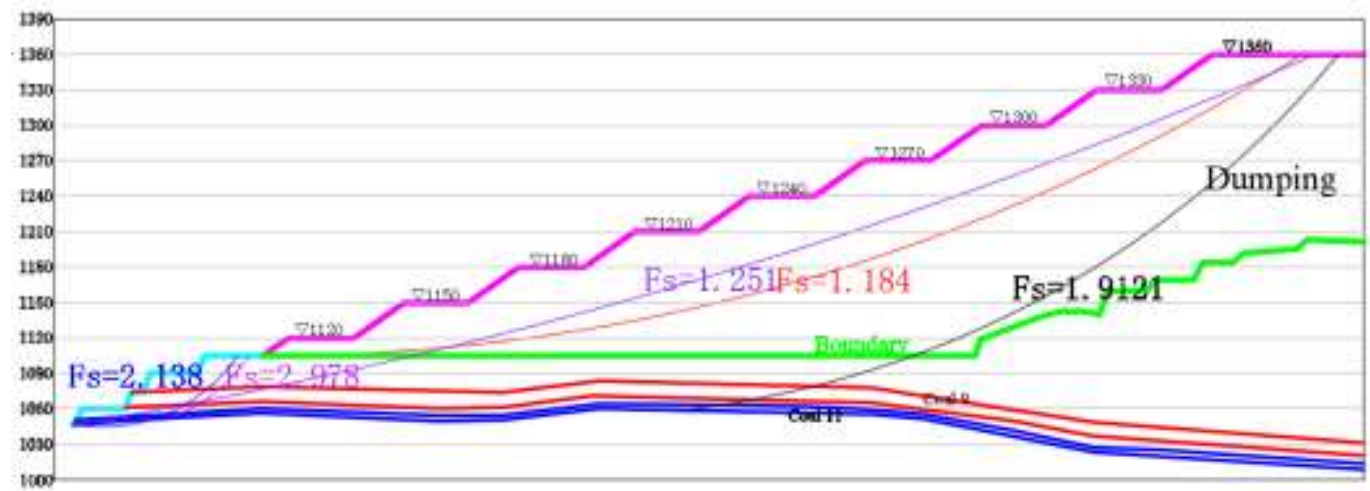

(a) Flat width $55 \mathrm{~m}$

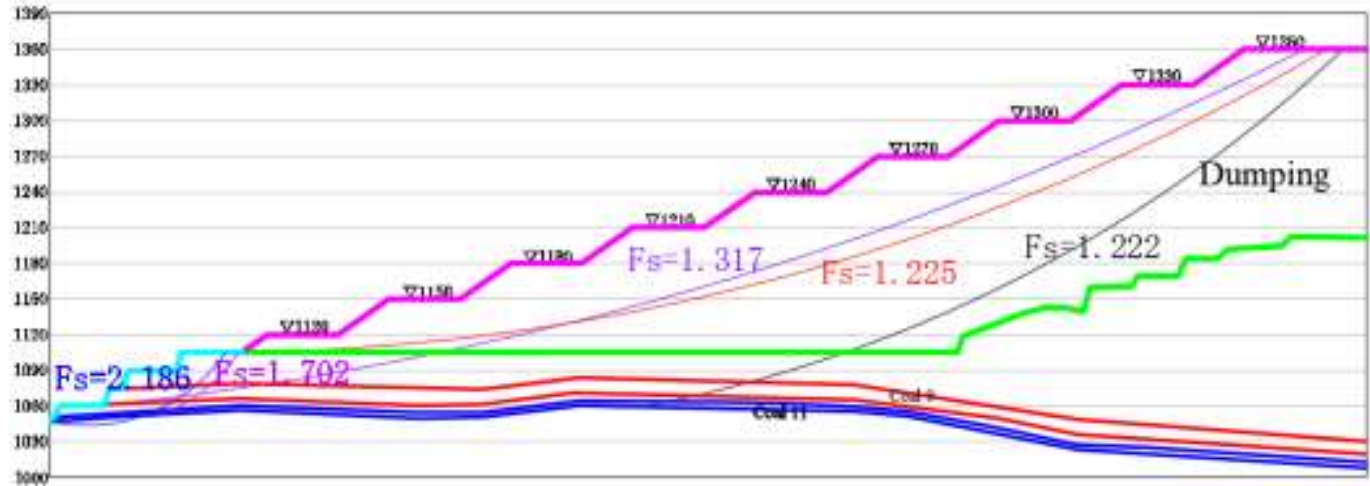

(a) Flat width $60 \mathrm{~m}$

Fig.5: Analysis results of slope stability in section I-I when the safe distance is $50 \mathrm{~m}$

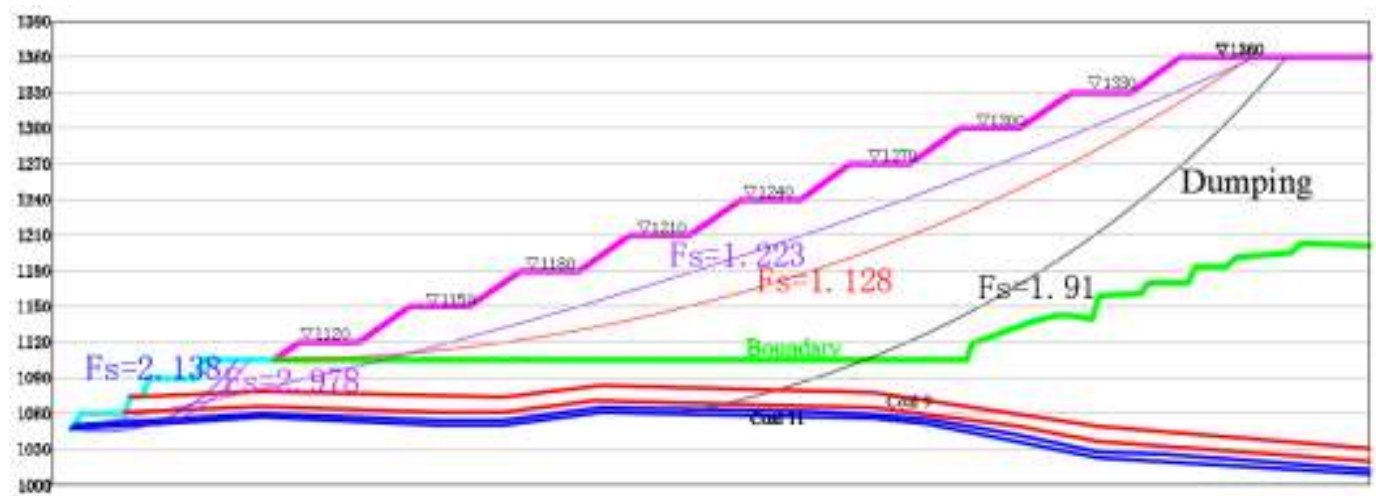

(a) Flat width $50 \mathrm{~m}$

ISSN: 0010-8189 


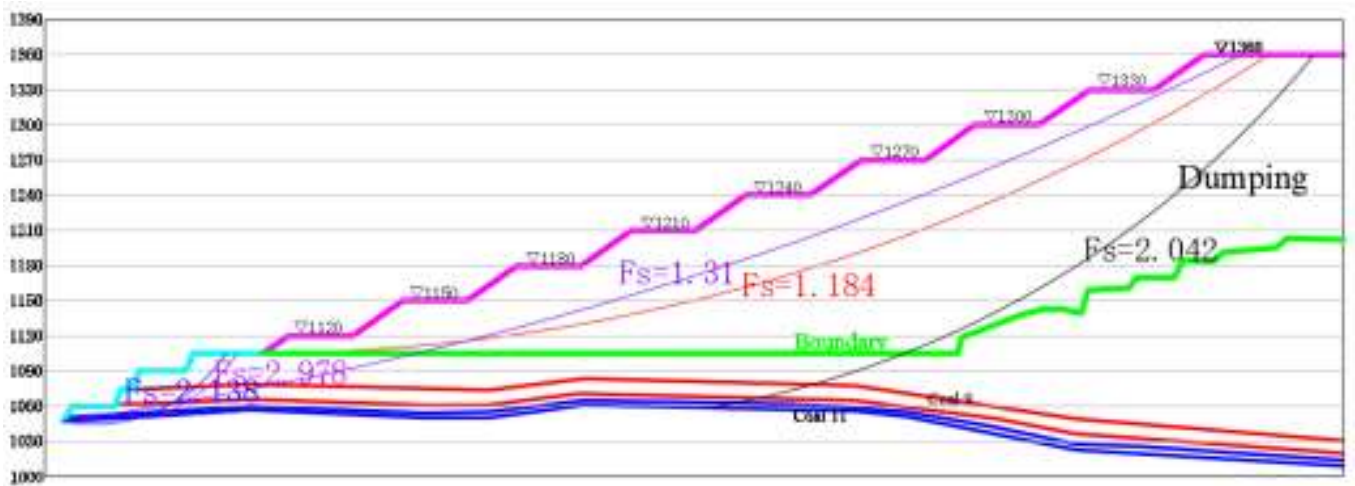

(a) Flat width $55 \mathrm{~m}$

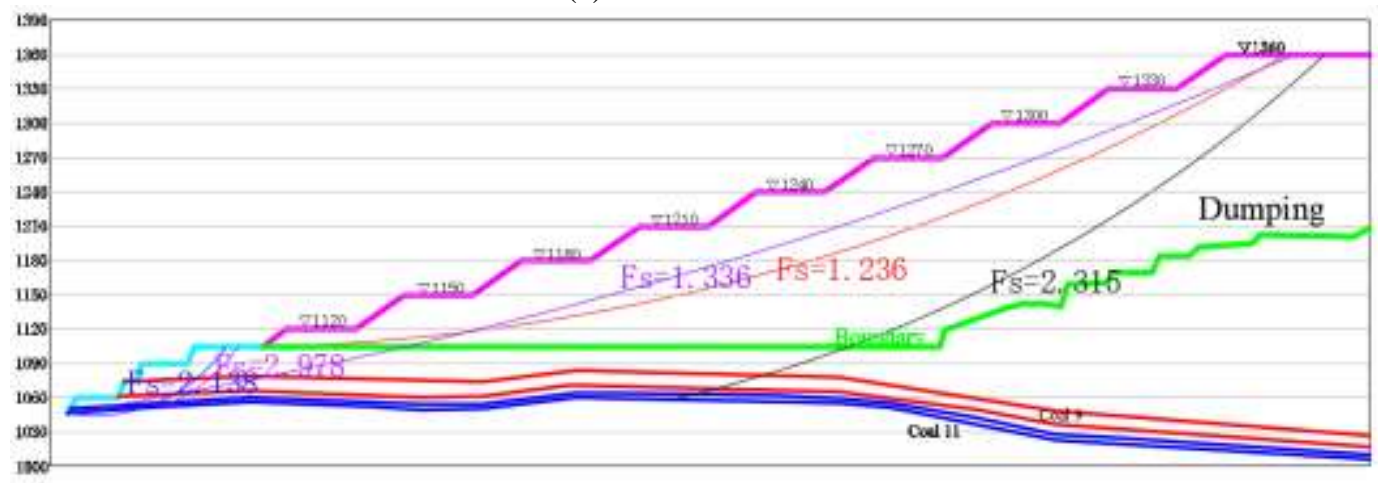

(a) Flat width $60 \mathrm{~m}$

Fig.6: Analysis results of slope stability in section I-I when the safe distance is $60 \mathrm{~m}$

Tab 2 Calculation results of slope stability in I-I profile with different safety distances and width of plate

\begin{tabular}{cccccccc}
\hline Scheme & Safe distance & Width /m & $\begin{array}{c}\text { Slope angle of } \\
\text { battery limit }{ }^{\circ}\end{array}$ & $\begin{array}{c}\text { Slope angle } \\
\text { of dump } /{ }^{\circ}\end{array}$ & Fs & $\begin{array}{c}\text { Rejection } \\
\text { height/m }\end{array}$ & $\begin{array}{c}\text { Discharge } \\
\text { volume/ } \\
10000 \mathrm{~m}^{3}\end{array}$ \\
\hline Scheme 1 & & 50 & 18.9 & 18.5 & 1.113 & 75 & 1602.02 \\
Scheme 2 & 40 & 55 & 18.2 & 17.6 & 1.155 & 195 & 7057.47 \\
Scheme 3 & & 60 & 17.5 & 16.8 & 1.192 & 195 & 6706.07 \\
Scheme 4 & & 50 & 18.7 & 18.5 & 1.116 & 75 & 1595.12 \\
Scheme 5 & 50 & 55 & 18 & 17.6 & 1.175 & 195 & 6750.84 \\
Scheme 6 & & 60 & 17.3 & 16.8 & 1.228 & 255 & 9593.41 \\
Scheme 7 & & 50 & 18.5 & 18.5 & 1.128 & 75 & 1588.22 \\
Scheme 8 & 60 & 55 & 17.8 & 17.6 & 1.184 & 195 & 6444.21 \\
Scheme 9 & & 60 & 17.1 & 16.8 & 1.236 & 255 & 8394.21 \\
\hline
\end{tabular}

According to Table 2, the dumping plans that satisfy the composite slope safety coefficient 1.2 include: plan 6 and plan 9. From the established three-dimensional geological model of Pingshuo Antaibao open-pit mine and the block model operand, it can be known that: the total dumping amount of Plan 6 and Plan 9 is 95,934,100 $\mathrm{m}^{3}$ and $83,942,100 \mathrm{~m}^{3}$, respectively. By comparison, Plan 6 can achieve the maximum dumping volume in the southern limited boundary zone on condition that the safety and stability coefficient is satisfied, which effectively relieves the dumping pressure and makes technology workable at reasonable economic costs. Therefore, Plan 6 is chosen as the plan for dumping soil in the limited boundary zone.

\subsubsection{II-II section slope stability calculation}

The direction of the dumping working line is mainly determined by the angle of the working line. The reasonable angle of the working line is obtained by calculating the safety and stability coefficient of the slope with different

ISSN: 0010-8189

Www.converter-magazine.info 
working line directions in the II-II section. Finally, the parameters of the composite slope on the southern slope of the limited boundary zone are obtained by combining the calculation results of the sections I-I and II-II. The working line angle diagram of section II-II is shown in Fig 7. Fig. 7 (a) is the spatial sketch map of the working line angle. When the profile is selected, the profile line should be perpendicular to the direction of the working line on the dumping step. Therefore, the dumping working line angles are different, so the directions of the II-II profile lines are also different. Fig. 7 (b) is the plane sketch map of the working line angle. The left II-II profile line is the profile position corresponding to different working line directions.

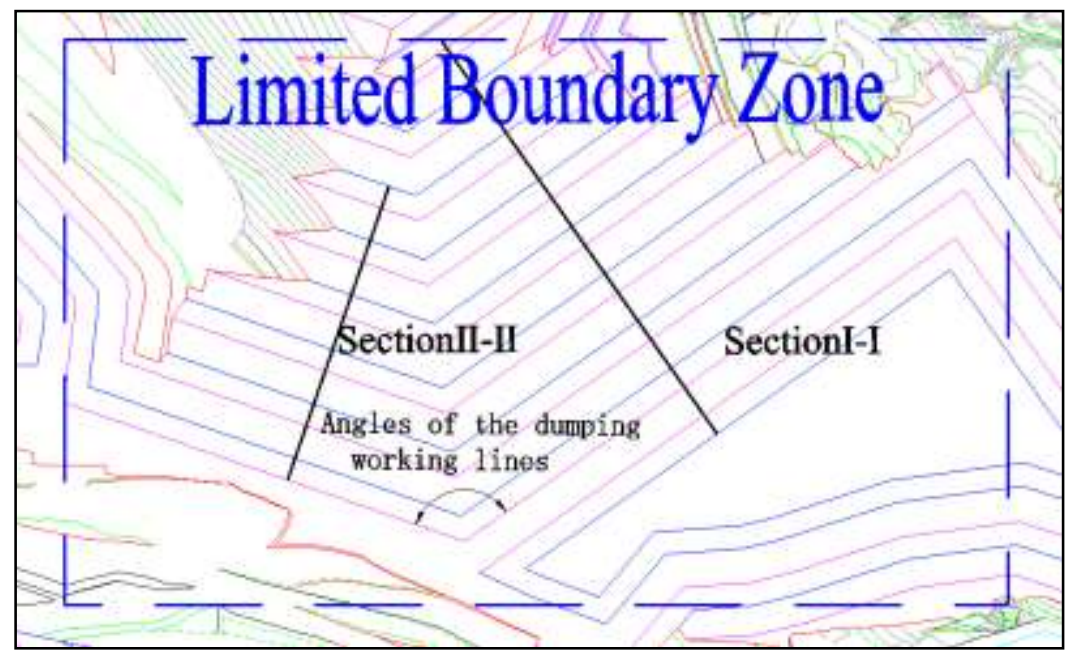

(a) Schematic diagram of working line angle space

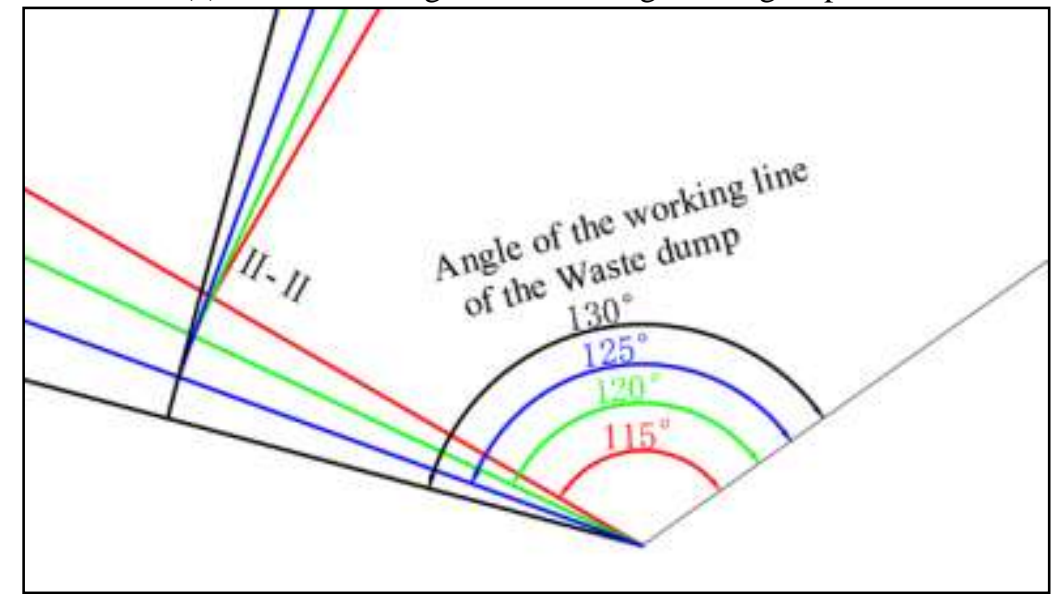

(b) Schematic diagram of working line angle plane

Fig.7: Section II-II position and working sketch line Angle

By changing the angle of the dumping working line on the southern slope of the limited boundary zone, the safety and stability coefficient of II-II section is first calculated when the dumping flat plate width is $60 \mathrm{~m}$, the dumping elevation is $1,360 \mathrm{~m}$, and the angles of the dumping working lines are different. Finally, the optimum working line angle of dumping is determined. Regarding the slope engineering conditions of II-II section, the slope stability coefficient is calculated when the dumping flat plate width is $60 \mathrm{~m}$, the dumping elevation is $1,360 \mathrm{~m}$, and the angles of the dumping working lines are $120^{\circ}, 125^{\circ}$ and $130^{\circ}$. The calculation results are shown in Fig. 8. Through calculation and analysis, the slope stability results of II-II section is shown in Table 3. 

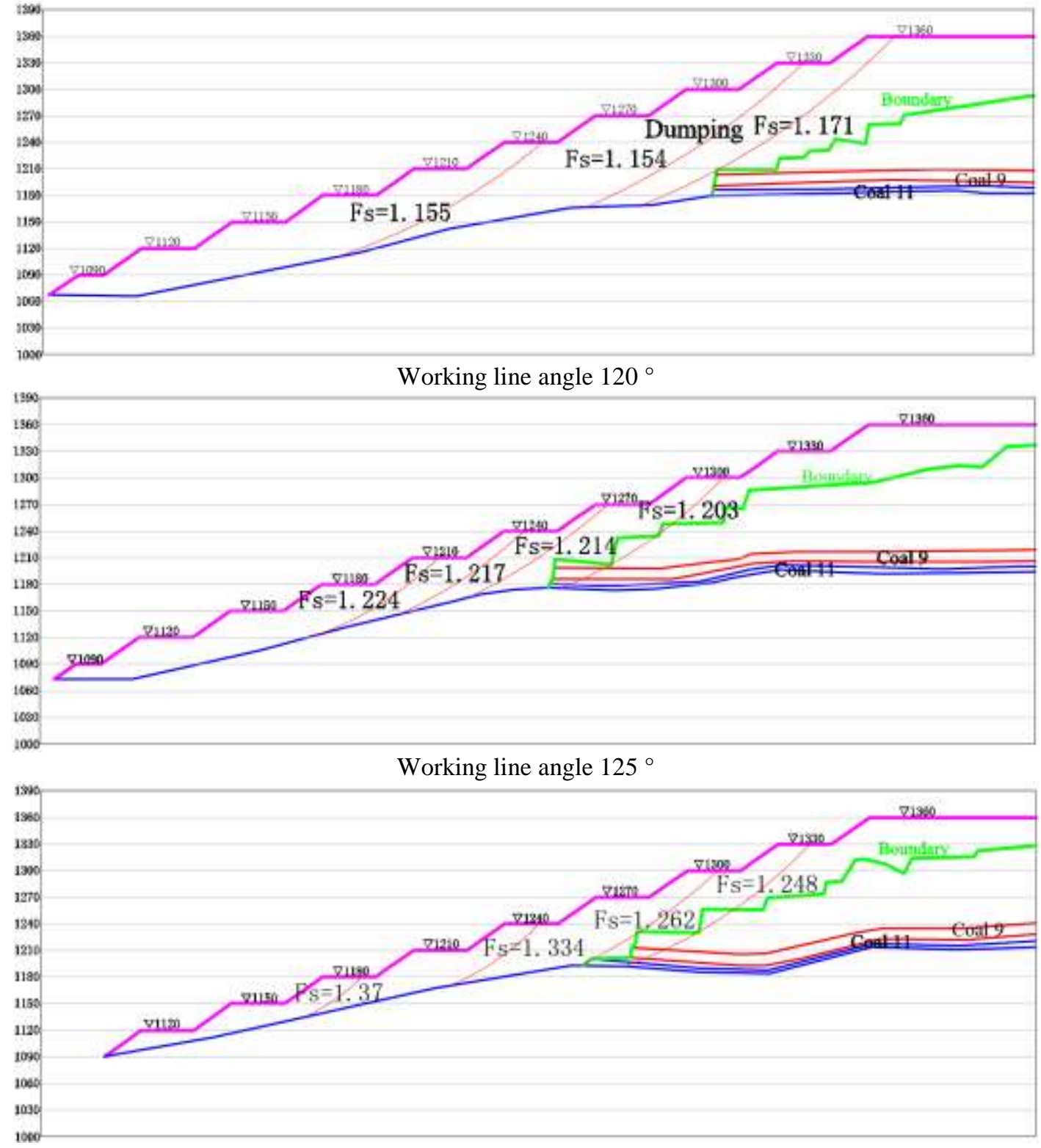

Working line angle $130^{\circ}$

Fig.8: Calculation results of slope stability of II-II section under different working line angles

Tab 3 Section II-II slope stability calculation results table

\begin{tabular}{cccc}
\hline Working line angle $/^{\circ}$ & Width of dumping pan $/ \mathrm{m}$ & Rejection height $/ \mathrm{m}$ & Fs \\
\hline 120 & 60 & 1360 & 1.154 \\
125 & 60 & 1360 & 1.203 \\
130 & 60 & 1360 & 1.248 \\
\hline
\end{tabular}

When the included angle of the dumping working line is $125^{\circ}$ and the slope stability coefficient is 1.203 , the safety reserve coefficient is satisfied. Meanwhile, the landslide pattern of the slope is a combination of tangent sliding and translational sliding.

The calculation results of I-I section and II-II section are combined to obtain the reasonable economic parameters of the composite slope on the southern slope of the limited boundary zone. They are as follows: the safe distance between the stope slope and the dump is $50 \mathrm{~m}$, the dumping flat plate width is $60 \mathrm{~m}$, and the angle of the dumping

ISSN: 0010-8189 
working line is $125^{\circ}$.

\section{Numerical Simulation}

The traditional two-dimensional limit equilibrium method fails to study the complex stress analysis and constitutive relationship within the rock and soil materials. Moreover, it also can't accurately describe the process of slope instability caused by changes in the internal structure of the slope. FLAC ${ }^{3 \mathrm{D}}$ is a method to simulate and analyze the geometry based on Lagrange difference method, and it is widely used in the analysis of discontinuity and nonlinearity in the rock mass structure. To a certain extent, it can avoid the difference that sliding body is regarded as rigid body in the two-dimensional analysis process. Therefore, numerical simulation should be used as a supplement in studying the stress-strain relationship and stress distribution of the slope rock mass. Therefore, FLAC $^{3 \mathrm{D}}$ software is used in this section to simulate the composite slope on the southern slope of the limited boundary zone at Antaibao open-pit mine. The three-dimensional slope calculation model should be close to the engineering practice, so that the calculation model and calculation results are more accurate. Due to the complexity of FLAC ${ }^{3 \mathrm{D}}$ modeling, 3DMine and Rhinoceros software are used for modeling pre-processing, and then mesh is divided for the 3D geological model. Based on the data collected on the composite southern slope of the limited boundary zone at Antaibao open-pit mine, the safe distance between the stope slope and the dump is $50 \mathrm{~m}$ and the dumping flat plate width is $60 \mathrm{~m}$ and the angle of the dumping working line is $125^{\circ}$. And then FLAC ${ }^{3 \mathrm{D}}$ model for the southern slope of the limited boundary zone is established through stratification, as shown in Fig. 9(a). The stratified model diagram of numerical simulation is shown in Fig. 9 (b).

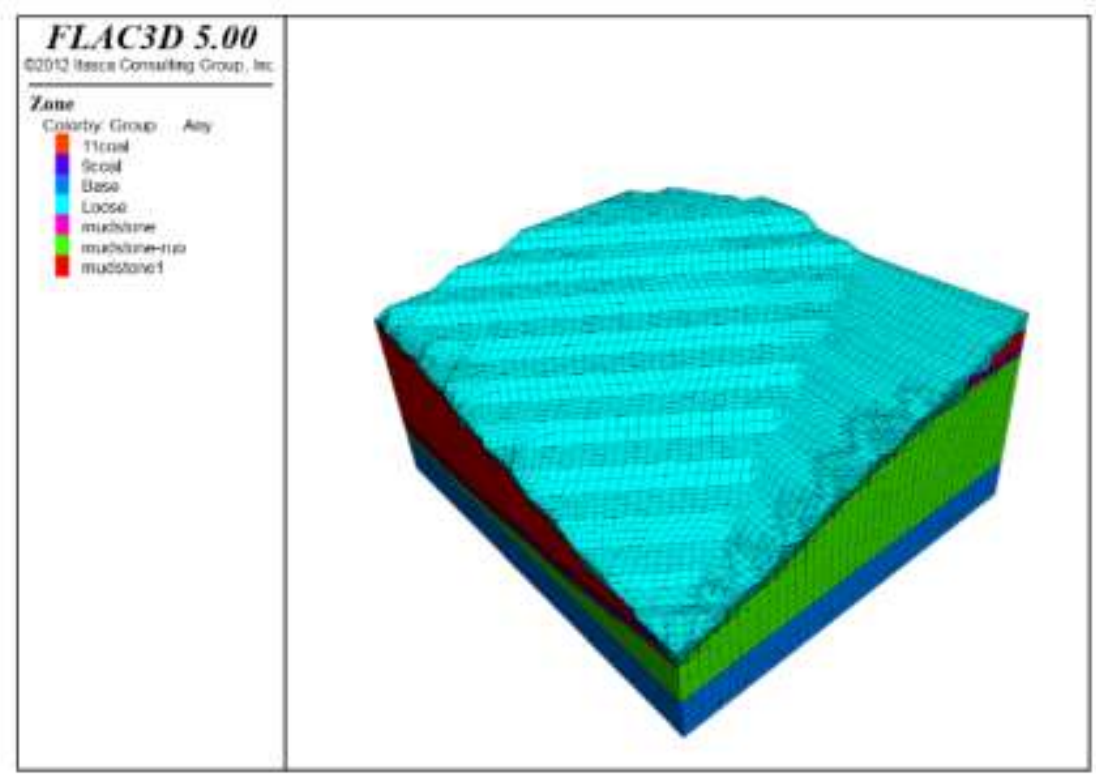

(a) Three dimensional numerical simulation model diagram 


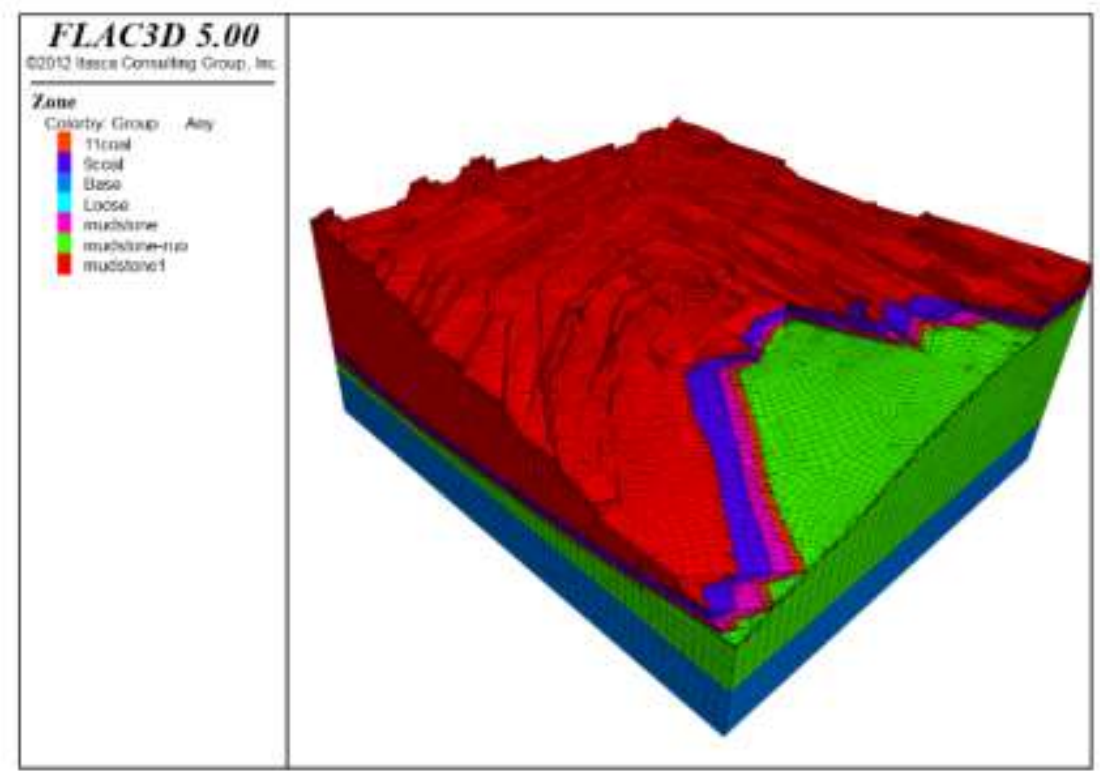

(b) Layered model of Three dimensional numerical simulation

Fig.9: Three-dimensional numerical simulation layered modelIn the diagram of numeric simulation, 290,998 units and 128, 638 nodes are divided, respectively. According to the geological conditions on the southern slope of the limited boundary zone at Antaibao open-pit mine. The corresponding three-dimensional slope model is made up of dumped materials, sandstones, 9 coal, sand-mudstone, 11 coal, soft mudstones and basements from top to bottom.

The numeric simulation results of the slope stability in I-I and II-II sections are shown in Fig. 10.

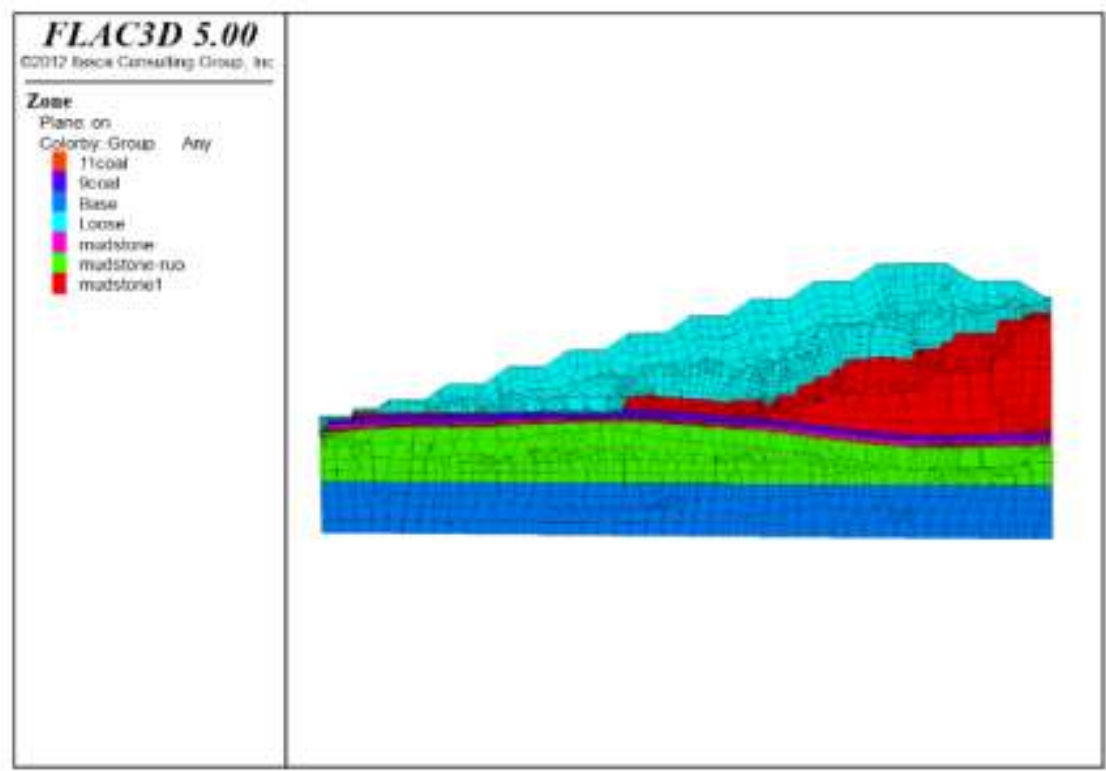

(a) Three dimensional numerical simulation model of section I-I 


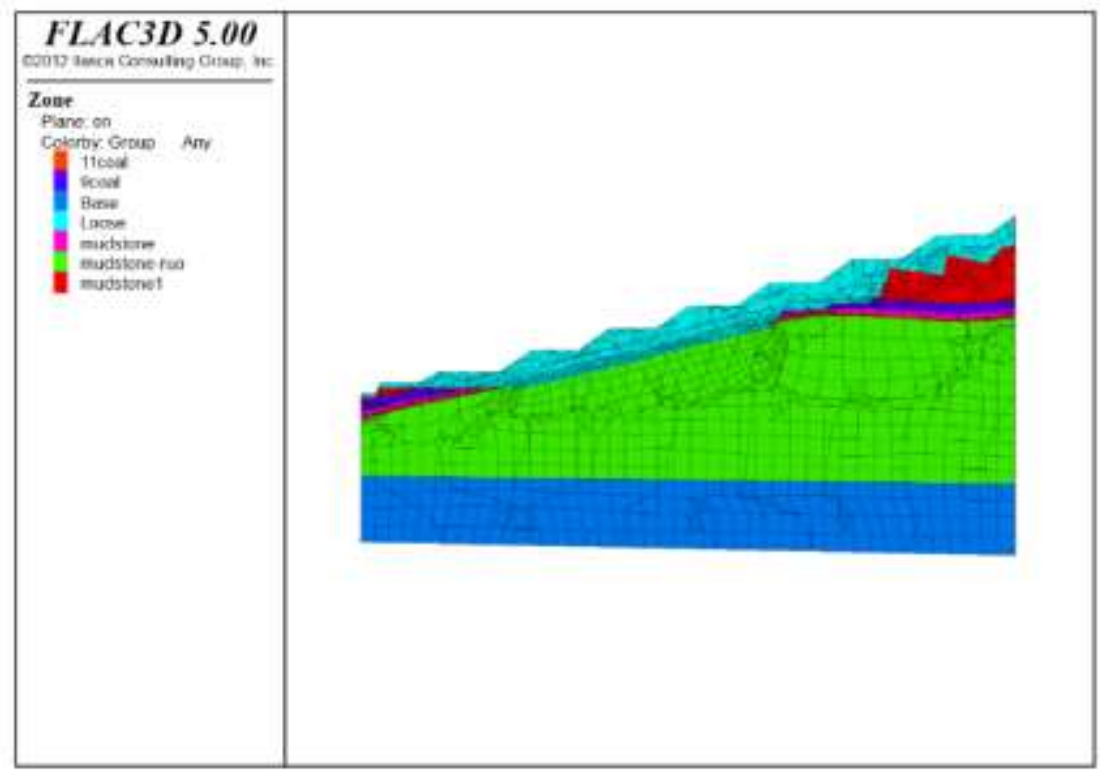

(b) Three dimensional numerical simulation model of section II-II

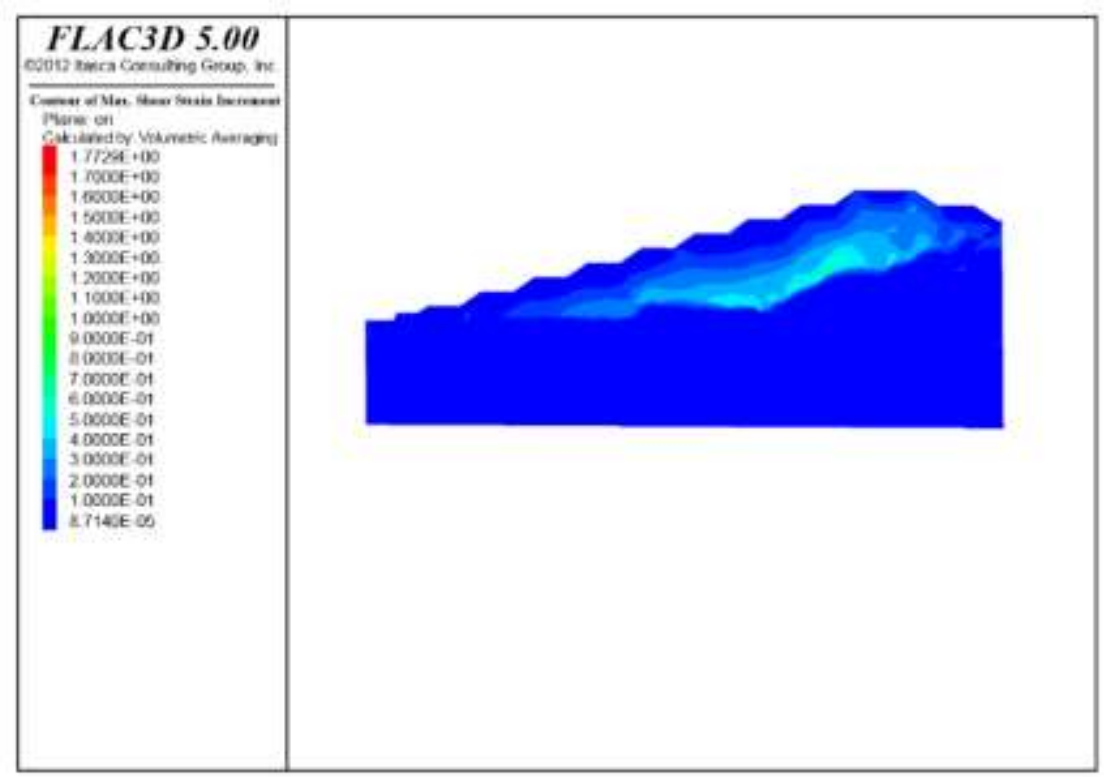

(c) Shear strain increment diagram of section I-I 


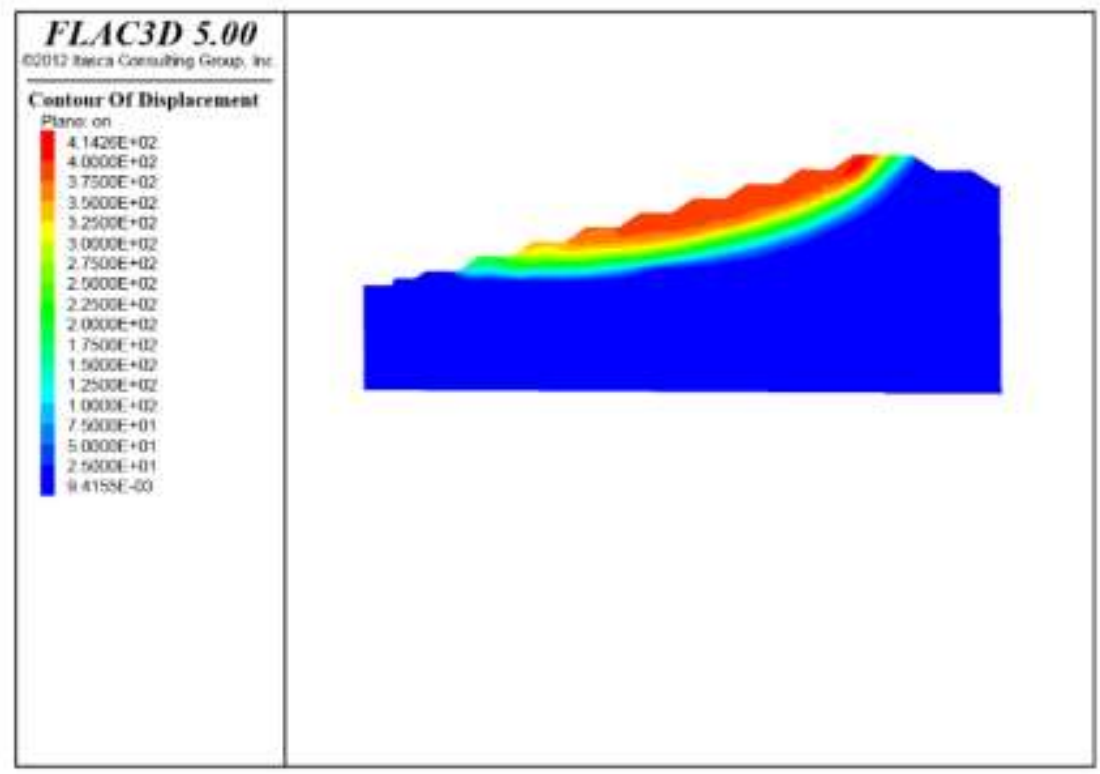

(d) Maximum displacement map of section I-I

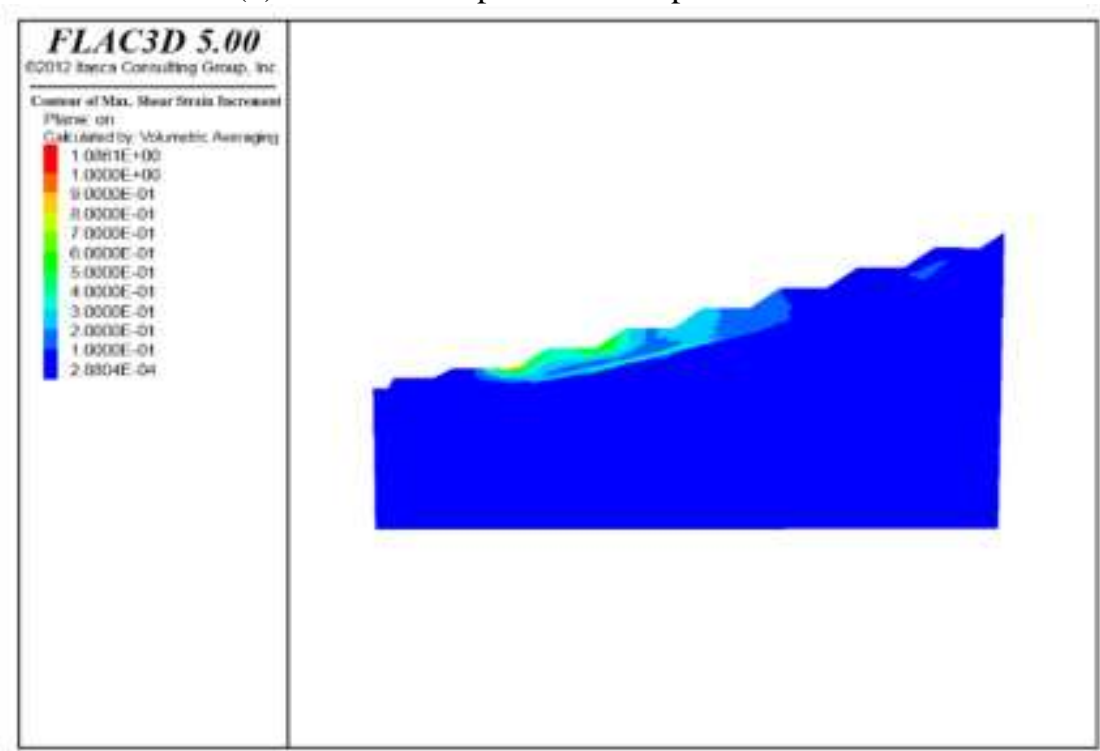

(e) Shear strain increment nephogram of section II-II 


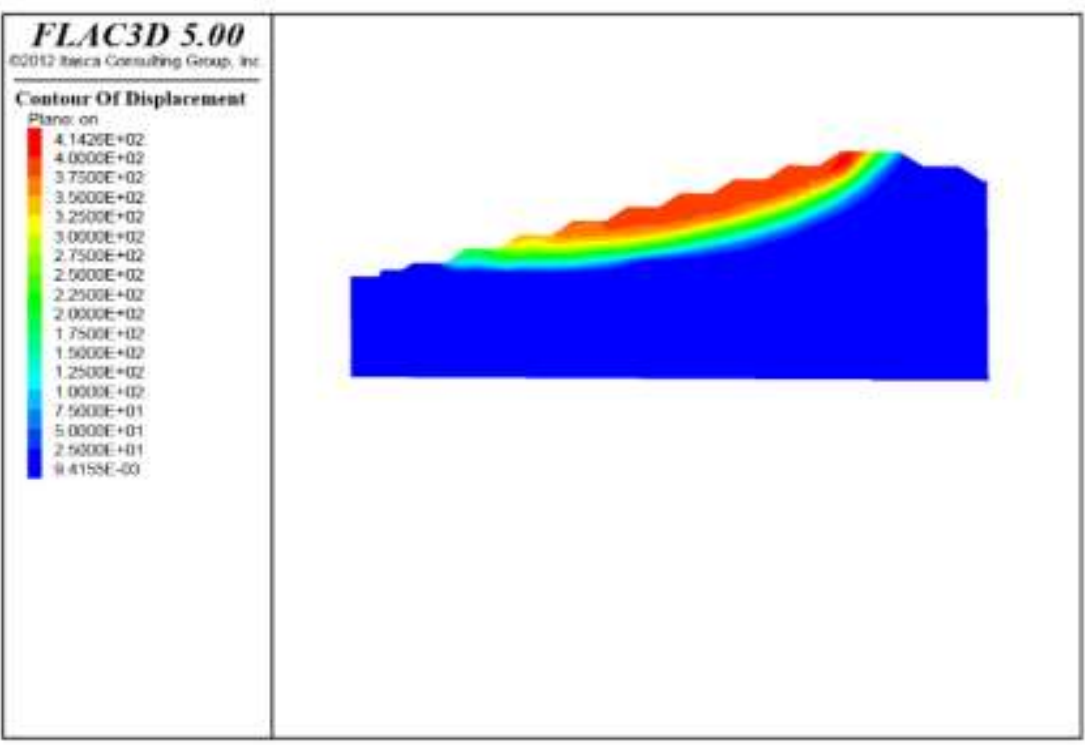

(f) Maximum displacement nephogram of section II-II Fig.10: Slope numerical simulation

(1) Fig. 10 (c) is the shearing stress increment figure when the I-I section slope is at critical failure, and Fig. 4.4 (e) is the shearing stress increment graph when the I-I section slope is at critical failure. It could be known from the simulation results that the rock mass damage of the slope is mainly caused by shearing strain. The positions of the stress concentration, the potential positions of the failure surface and the obvious stress changes can be clearly seen in the Fig.

(2) Fig. 10 (d) is the maximum displacement figure when the I-I section slope is at critical failure. It can be clearly seen from the figure that the slope makes circular slide easily along the dumped materials under the impact of dead load and crustal stress. Fig. 4.4 (f) is the maximum displacement figure when the II-II section slope is at critical failure. It can be clearly seen from the figure that the displacement changes appear along the shear failure of 11 coal floor. When the slope is under the impact of dead load and crustal stress, the combined failure of tangent sliding and translational sliding easily happen along 11 coal floor.

The paper aimed at the composite slope forms on the southern slope of the limited boundary zone at Antaibao open-pit mine. Based on the results achieved through the quantiative method of the two-dimensional slope stability and the strength reduction theory, FLAC ${ }^{3 \mathrm{D}}$ finite difference calculation software was used for the three-dimensional numeric simulation calculation of the composite slope. The simulated result is consistent with the analyzed result of the two-dimensional limit equilibrium method. Meanwhile, they verified the sliding pattern.

\section{Conclusions}

(1) When the slope is under the combined action of dead load and crustal stress, the shear failure happens inside the slope. The sliding pattern is a combination of circular sliding and the tangent-translational sliding.

(2) Through the integration of I-I section and II-II section, the rigid limit equilibrium method was used to obtain the reasonable economic parameters of the composite slope on the southern slope of the limited boundary zone. They are as follows: the safe distance between the stope slope and the dump is $50 \mathrm{~m}$, the dumping flat plate width is $60 \mathrm{~m}$, the dumping elevation is $255 \mathrm{~m}$, the angle of the dumping working line is $125^{\circ}$ and the total dumping space is $95,934,100 \mathrm{~m}^{3}$.

(3) FLAC $^{3 \mathrm{D}}$ numeric simulation software was used for the simulated calculation of the southern composite slope in the limited boundary zone. It could be known that the sliding pattern and the stability of the composite slope are

ISSN: 0010-8189 
mainly controlled by the safe distance between the stope slope and the dump together with the soft layers of 11 coal bed. In addition, the simulated result was consistent with the analyzed result of the two-dimensional limit equilibrium method. It proved that the sliding pattern is a combination of circular sliding and tangent-translational sliding.

\section{Acknowledgements}

This research was supported by National Natural Science Foundation of China (Grant No. 51974144).

\section{References}

[1] Y.Y. Xia, M. LI, “Research and Development Trend of slope Stability Evaluation methods," Journal of Rock Mechanics and Engineering, vol. 07, pp. 1087-1091, 2002.

[2] C.G. Huang, E.B. Ding, "Stability analysis methods commonly used in slope Engineering," Design of Hydropower Stations, vol. 01, pp. 54-59, 1999.

[3] Y.X. Zhang, "Slope Engineering," Beijing: China Building Industry Press, pp. 4-8, 2008.

[4] B. Chen, M.N. LI, A.Q. Pang, "Slope Stability Analysis of open-pit Mine," Inner Mongolia Coal Economy, vol. 10, pp. 96-106, 2019.

[5] C. Romer, M. Ferentinou, "Numerical investigations of rock bridge effect on open pit slope stability," Journal of Rock Mechanics and Geotechnical Engineering, 2019.

[6] M.J. Li, "Compound soft rock slope deformation mechanism analysis," Coal science and technology: 1-6 [2020-07-26]. http://kns.cnki.net/kcms/detail/11.2402.TD.20200215.1826.004.html.

[7] L.Z. Cao, G.H. LI, D. Wang, "Optimization of empty form of soil-rock compound overdip Slope in open pit mine,” Metal Mine, vol. 09, pp. 49-52, 2016.

[8] R.C. Bai, W.Z. Bai, G.W. Liu, Y.G. Sun, "Study on stability and Application of Composite Slope with Weak Layer," Journal of Liaoning University of Engineering and Technology (Natural Science edition), vol. 37, no. 01, pp. 61-65, 2016.

[9] R.W. Li, E.K. Hou, T.L. Liu, "Stability analysis of composite Slope in open-pit Coal Mines based on THREE-DIMENSIONAL Numerical Simulation,” Coal Field Geology and Exploration, vol.02,pp. 43$51,2008$.

[10] C.L. Sun, "Study on the Stability of the North Side of yilan Open-pit Mine Out-side Dump and stope Topside Composite Slope," Liaoning University of Engineering and Technology, 2016.

[11] Garmondyu E. Rusoe Jr, "Study on formation, deformation and Instability mechanism and Optimization of Key Factors of composite slope in open pit mine," China University of Mining and Technology, 2017.

[12] R. Lao, K.H. Ma, P. Zhou, B. Wang, "Analysis of slope stability in open-pit mines by the combination of limit equilibrium method and finite element Method," Mining Engineering, vol. 17, no. 01, pp. 1417, 2019.

[13] Y. Zheng, S.Y. Zhao, "Application of finite element Strength reduction method in soil slope and rock slope," Journal of Rock Mechanics and Engineering, vol. 19, pp. 3381-3388, 2004.

[14] R.C. Liu, "Optimization calculation Method of composite sliding surface of open pit Slope under the influence of weak layer,” Open pit Mining Technology, vol. 2, pp. 27-29, 2013.

[15] X. Yao, "Study on the Stability of complex slope of Stope and dump in Zhundong Open Pit Mine," Liaoning University of Engineering and Technology, 2015.

[16] W.L. Tang, "Study on the Stability of composite slope and Mining Control Technology of Zahaur Open-pit Mine," China University of Mining and Technology, 2017.

[17] Y.S. Fang, "Discussion on the role of landslide stability in the value of landslide safety coefficient," Chinese Journal of Geological Hazards and Prevention, vol. 03, pp. 149-153, 2007.

[18] GB50197-2015, Design Specification for coal Industry Open-pit mine. Beijing: China Planning Press, 2015. 